\title{
Aims and tasks in parental caregiving for children receiving palliative care at home: a qualitative study
}

\author{
Lisa M. Verberne ${ }^{1}$ - Marijke C. Kars ${ }^{1}$ • Antoinette Y. N. Schouten-van Meeteren ${ }^{2}$. \\ Diederik K. Bosman ${ }^{3}$ • Derk A. Colenbrander ${ }^{3}$ - Martha A. Grootenhuis ${ }^{4,5}$. \\ Johannes J. M. van Delden ${ }^{1}$
}

Received: 26 July 2016 / Revised: 6 December 2016 / Accepted: 23 December 2016 / Published online: 11 January 2017

(C) The Author(s) 2017. This article is published with open access at Springerlink.com

\begin{abstract}
In paediatric palliative care (PPC), parents are confronted with increasing caregiving demands. More children are cared for at home, and the need for PPC of children is lengthened due to technical and medical improvements. Therefore, a clear understanding of the content of parental caregiving in PPC becomes increasingly important. The objective is to gain insight into parental caregiving based on the lived experience of parents with a child with a life-limiting disease. An interpretative qualitative study using thematic analysis was performed. Single or repeated
\end{abstract}

Revisions received: 04 November 2016; 07 Dec 2016; (2) Provided Funding information has to be tagged.

Communicated by David Nadal

Electronic supplementary material The online version of this article (doi:10.1007/s00431-016-2842-3) contains peer-reviewed but unedited supplementary material, which is available to authorised users.

Lisa M. Verberne

1.m.verberne@umcutrecht.nl

Marijke C. Kars

m.c.kars@umcutrecht.nl

Antoinette Y. N. Schouten-van Meeteren

a.y.n.schouten@amc.uva.nl

Diederik K. Bosman

d.k.bosman@amc.uva.nl

Derk A. Colenbrander

d.a.colenbrander@amc.uva.nl

Martha A. Grootenhuis

M.A.Grootenhuis-2@prinsesmaximacentrum.nl interviews were undertaken with 42 parents of 24 children with a malignant or non-malignant disease, receiving PPC. Based on their ambition to be a 'good parent', parents caring for a child with a life-limiting disease strived for three aims: controlled symptoms and controlled disease, a life worth living for their ill child and family balance. These aims resulted in four tasks that parents performed: providing basic and complex care, organising good quality care and treatment, making sound decisions while managing risks and organising a good family life.
Johannes J. M. van Delden

j.j.m.vandelden@umcutrecht.nl

1 Department of Medical Humanities, Julius Center for Health Sciences and Primary Care, University Medical Center Utrecht, Heidelberglaan 100, 3508 GA Utrecht, The Netherlands

2 Department of Pediatric Oncology, Emma Children's Hospital, Academic Medical Center, Meibergdreef 9, 1105 AZ Amsterdam, The Netherlands

3 Department of Pediatrics, Emma Children's Hospital, Academic Medical Center, Meibergdreef 9, 1105 AZ Amsterdam, The Netherlands

4 Psychosocial Department, Emma Children's Hospital, Academic Medical Center, Meibergdreef 9, 1105 AZ Amsterdam, The Netherlands

5 Princess Máxima Center for Pediatric Oncology, Lundlaan 6, 3584 AE Utrecht, The Netherlands 
Conclusion: Parents need early explanation from professionals about balancing between their aims and the related tasks to get a grip on their situation and to prevent becoming overburdened.

\section{What is Known:}

- In paediatric palliative care, parents are confronted with increasing caregiving demands.

- Parenting is often approached from the perspective of stress.

What is New:

- Parents strive for three aims: controlled symptoms and controlled disease, a life worth living for their child and family balance.

- Parents perform four tasks: providing basic and complex care, organising good quality care, making decisions while managing risks and organising a good family life.

- Professionals need insight into the parents' aims and tasks from the parental perspective to strengthen parents' resilience.

Keywords Family adjustment · Parental caregiving · Parenting $\cdot$ Paediatric palliative care $\cdot$ Home care

$\begin{array}{ll}\text { Abbreviations } \\ \text { ADL } & \text { Activities of daily living } \\ \text { EOL } & \text { End-of-life } \\ \text { HCP } & \text { Healthcare professional } \\ \text { LLD } & \text { Life-limiting disease } \\ \text { MD } & \text { Malignant disease } \\ \text { NMD } & \text { Non-malignant disease } \\ \text { PPC } & \text { Paediatric palliative care } \\ \text { PPCT } & \text { Paediatric palliative care team } \\ \text { PTSD } & \text { Post-traumatic stress disorder }\end{array}$

\section{Introduction}

In paediatric palliative care (PPC), most seriously ill children are predominantly cared for at home $[18,31,43]$. Therefore, parents of a child with a life-limiting disease (LLD) are confronted with increased caregiving demands, and also have to cope with the inevitability of a premature death of their child [12]. The spectrum of LLDs requiring palliative care during childhood is broad and heterogeneous. LLDs are generally divided into four categories (Table 1) [1]. The duration of PPC and the needs of these children vary widely among the categories.

Because PPC is a relatively young specialty, current knowledge on parental caregiving mainly relies on studies in chronically ill children, not facing life-limiting issues of their disease and in children treated for cancer. It shows that the parenting role intensifies and expands beyond routine physical care $[21,33,38,44,48]$. This expanded parenting role includes nursing, technical and emotional tasks, such as providing childcare, learning about the disease and its treatment options, managing their child's disease, organising all aspects of their child's daily life and care and managing their own particular situation [4, 11, 12, 21, 39, 44, 47, 48].

Studies on parental caregiving in PPC are mainly performed in paediatric oncology and focus on the end-of-life (EOL). Besides the expansion of caregiving tasks, these studies show that parents have to deal with uncertainty and to adapt to an accumulation of losses related to their child's physical and functional decline $[6,14,26]$. Although parents intend to act in their child's best interest, including a good death, many of them struggle with facing reality and the timely transition from preserving their child at all costs towards being prepared to let their child die $[2,10,14,16,23]$. Moreover, parents emphasise they have to 'navigate uncharted territory' and lack professional guidance, resulting in feelings of isolation and abandonment $[15,37]$. A recent review on chronic care situations in children showed the discrepancy between the parental learning needs and the information provided by healthcare professionals (HCPs), stressing the necessity to elicit the parents' perspectives and to take the families' complete situation into account [30].

Paediatric illnesses or injuries affect many children and parents because they are often brought into healthcare settings under adverse and often life-threatening circumstances [20, 32]. These circumstances concern potentially traumatic medical experiences that might lead to stress responses [20]. As such, parenting a seriously ill child is often approached from the perspective of stress $[38,48]$, as is represented in the paediatric medical traumatic stress model [20, 32]. In PPC, parental caregiving is also considered distressing and potentially traumatic for parents $[25,32,36]$, since living towards a child's death understandably causes disruption and grief [12]. Studies indicate that parents of children with a LLD, who perceive a high risk of life threat and complications, are at increased risk of post-traumatic stress disorder (PTSD) [19, 32]. While HCPs cannot protect parents from such risks, they should however try to strengthen the parents' resilience and prevent distress as much as possible $[12,34,35]$. This starts with an understanding of parental caregiving from the parents' perspective. In addition, since driven by technical and medical improvements PPC may last over many years, a clear understanding of the content of parental caregiving in PPC from the parents' perspective becomes increasingly important. Therefore, the aim of this article is to provide a generic and comprehensive overview of parental caregiving, based on the lived experience of parents caring for a child with a LLD.

\section{Methods}

To elucidate the parents' perspective, we conducted an interpretative qualitative interview study using an inductive thematic analysis $[3,8,40]$. This study was part of a larger study 
Table 1 Categories of life-limiting diseases [1]

\begin{tabular}{lll}
\hline Category & Description & Examples \\
\hline Category 1 & $\begin{array}{c}\text { Life-threatening conditions for which curative treatment may } \\
\text { be feasible but can fail. Where access to palliative care } \\
\text { services may be necessary when treatment fails or during } \\
\text { acute crisis, irrespective of the duration of that threat to life } \\
\text { Conditions where premature death is inevitable, where there } \\
\text { may be long periods of intensive treatment aimed at } \\
\text { prolonging life and allowing participation in normal } \\
\text { childhood activities }\end{array}$ & Cancer; irreversible organ failure of heart, liver or kidney \\
& $\begin{array}{l}\text { Progressive conditions without curative treatment options, in } \\
\text { which treatment is exclusively palliative and may } \\
\text { commonly extend over many years }\end{array}$ & Batten's disease; mucopolysaccharidoses \\
Category 3 & $\begin{array}{c}\text { Irreversible but non-progressive conditions causing severe } \\
\text { disability, leading to susceptibility to health complications, } \\
\text { and likelihood of premature death }\end{array}$ & $\begin{array}{c}\text { Severe cerebral palsy; multiple disabilities such as following } \\
\text { brain or spinal cord injury }\end{array}$ \\
& & \\
\hline
\end{tabular}

to evaluate a pilot with a paediatric palliative care team (PPCT; Box 1). The focus of this article is to provide insight into parental caregiving in PPC from the parents' perspective. The role of the PPCT from the parents' perspective will be described in a separate article.

Box 1 Description of the paediatric palliative care team (PPCT)

In June 2012, the first Dutch PPCT was initiated as a 3-year pilot project at the Emma Children's Hospital in Amsterdam. The multidisciplinary PPCT consists of five specialised paediatric nurses trained and experienced in PPC, two child life specialists, a psychologist, a social worker and a chaplain. Additionally, two paediatric oncologists and two paediatricians are committed for regular consultation. The PPCT is responsible for the coordination, continuity and quality of PPC, irrespective of the child's place of residence. They strive to avoid acute demands for support by a proactive attitude. The support provided by the PPCT is continuous throughout the disease trajectory, including a 24-h availability and bereavement care. The PPCT bridges the gaps between home and hospital and navigates parents through the complex care processes by regular contact through phone calls, e-mails, and personal visits at home and during hospitalisations. In addition, the PPCT strengthens regular care at home by educating and coaching the other healthcare professionals involved. If regular care fails, the PPCT is competent and qualified to take over the care by providing temporary nursing care at home. For the possibility to discuss patients, maximum exchange of palliative care knowledge and optimal deployment and collaboration between team members, the PPCT has weekly multidisciplinary conferences.

\section{Sample}

A purposive sample of Dutch-speaking parents of children with a LLD primarily residing at home who were referred to the PPCT from a Dutch university children's hospital (Emma Children's Hospital, Amsterdam) was included. Referral to the PPCT ensured a general agreement among HCPs that PPC was indicated and thus provided access to families of children with a variety of diseases, who could maximally inform us about parental caregiving in PPC
[28]. To capture a wide range of perspectives, variation in selected children was sought with respect to malignant (MD) and non-malignant diagnoses (NMD) and phase of the disease trajectory that increases the need for PPC: the palliative trajectory. Based on literature, four phases of the palliative trajectory were distinguished: diagnostic phase, phase of loss of normality (adjusting to new normality), phase of decline and the dying phase [15, 45]. Parents of 35 cases were identified as eligible. A member of the PPCT or the treating physician introduced this study to the parents and asked permission for the researchers to contact them. In six identified cases, the introducing HCP considered the parents' situation too vulnerable to inform them about the study. Parents of 29 children were invited by telephone to participate by the researchers. In five cases, parents refused participation. Reasons for refusal were as follows: no time $(n=2)$, too burdensome $(n=2)$ and unknown reason $(n=1)$. In total, 24 mothers and 18 fathers of 24 children were interviewed. For patient characteristics, see Table 2. In three cases, parents $(n=6)$ were intentionally approached to participate after the child's death, and in three cases, a second interview after the child's death was performed with five parents to gain deeper insight into parental caregiving during the end-of-life and dying phase.

\section{Data collection}

In total, 47 individual open interviews took place at home. The interviews were held between August 2013 and November 2015 and lasted from $30 \mathrm{~min}$ to $2 \mathrm{~h}$. The interviewers (LV, $\mathrm{MK}, \mathrm{MB}$ ) were independent researchers from a different university from where the PPCT is seated. A topic list (Supplement 1) based on literature and experts' knowledge was used to guide the interviews. Topics relevant for this study were parenting, parental caregiving, care facilities, parents' 
Table 2 Characteristics of the parents $(n=42)$ and their ill child $(n=24)$

\begin{tabular}{lll}
\hline Characteristics & Number $(N)$ & Percentages (\%) \\
\hline
\end{tabular}

Gender parent

Male

Female

Age of parent ${ }^{\mathrm{a}}$

$<30$

$30-40$

$>40$

Marital stage

Married/cohabiting

Divorced/not cohabiting

Education

Low $^{\mathrm{b}}$

Middle $^{\mathrm{c}}$

High $^{\mathrm{d}}$

Age of child at first interview

$0-1$

$1-5$

$5-12$

$12-16$

$\geq 16$

Child gender

Male

Female

Child diagnosis

Non-malignant disease (total)

Congenital anomalies

Neurodegenerative disease

Metabolic disease

Malignant disease (total)

Central nervous system tumour

Bone/soft tissue sarcoma

Neuroblastoma

Leukaemia

Time since diagnosis

0-6 months

6-12 months

1-2 years

2-5 years

$>5$ years

Palliative phase at first interview

Diagnostic phase

Phase of loss of normality

Phase of decline

Dying phase

Siblings per case

0

1

2
18

24

2

29

9

38

4

5

15

22

$1^{\mathrm{e}}$

$13^{\mathrm{f}}$

7

2

1

12

12

15

11

2

2

9

5
Table 2 (continued)

\begin{tabular}{l} 
Characteristics \\
\hline 3 \\
\hline Percentages may not equal 100 due to rounding $(N)$ Percentages (\%) \\
${ }^{a}$ Age of two parents is missing \\
${ }^{\mathrm{b}}$ Low: primary school, lower secondary general education, lower voca- \\
tional education \\
${ }^{\mathrm{c}}$ Middle: higher secondary general education, intermediate vocational \\
education \\
${ }^{\mathrm{d}}$ High: higher vocational education, university \\
${ }^{\mathrm{e}}$ In one case, the interview took place after the child's death \\
${ }^{\mathrm{f}}$ In two cases, the interview took place after the child's death
\end{tabular}

life, self-efficacy and family life. Interviews were audio recorded and transcribed verbatim. The study was approved by the research ethics committee of the Academic Medical Centre Amsterdam (June 12, 2013; Reference number: W13_120 no. 13.17.0153). Written informed consent was obtained from all participating parents.

\section{Data analysis}

An inductive thematic analysis was used $[3,8,40]$ in accordance with methods that optimise validity and rigour [29]. During the entire process, three researchers (LV, MK, JvD) supported by a research assistant were involved. They used joint meetings to reach agreement on interpretation of the data and findings and worked towards consensus. Therefore, researcher triangulation was ensured to improve reliability and validity of the analysis.

The thematic analysis consisted of three phases. Firstly, the researchers (re)read the transcripts of eight interviews individually to get familiar with common aspects and phrases in the context of the interview $[3,8,40]$. At least two researchers analysed and initially coded with paper and pencil the eight transcripts individually and compared interpretations together. The meaning of the separate text fragments was determined by interpreting them in light of the whole interview [8, 22]. The initial codes were recoded, resulting in an adapted code list with themes and concepts at a more abstract and conceptual level [8].

During the second phase, every new interview was read and discussed by at least two researchers. One researcher (LV) and a trained research assistant coded all transcripts, supported by the software program NVivo10. After coding each transcript, the code tree was evaluated and, if necessary, revised. The different codes were sorted into potential themes, which were defined and refined [3]. To guide constant comparison, the research team went back and forth between the different steps and the entire dataset to capture the key aspects of the themes in the raw transcripts. 
Thirdly, the researchers identified the relationship between the themes [3] and integrated the themes into a descriptive model [40]. To ensure validity and provide transparency of the results, an audit trail was made by the core members of the research team (LV, MK, JvD), in consultation with the other researchers involved in this study, to record methodological choices and substantive ideas and concepts related to the interpretation of the data. Saturation was reached on a conceptual level. The results were externally validated by two parent association representatives, respectively for children with malignant and non-malignant diseases. In addition, we checked our findings in an expert meeting among nine HCPs experienced in paediatrics, PPC and/or homecare. This has not led to adjustments of the results.

\section{Results}

\section{Being a 'good parent'}

All parents expressed their ambition to be a good parent for their child in the extraordinary situation of knowing that their child's life is limited and within an unknown time span where they will have to direct their child's EOL. In response to the perceived vulnerability, the disease-related suffering and the efforts their child had to make due to his/her illness, parents desired to be the best parents their child could wish for. The wish to be a good parent became manifest in three aims parents consciously or unconsciously strived for, as identified from their narratives. In addition, four groups of tasks connected to the aims were identified (Fig. 1). First, the aims and the way parents struggled to achieve the aims are described. Then, the related parental tasks are presented. Representative quotations were chosen to illustrate the identified aims and tasks (Tables 3 and 4).

\section{Aims}

The parents' aims were (1) controlled symptoms and controlled disease, (2) a life worth living and (3) family balance.

\section{Controlled symptoms and controlled disease}

All parents described that it was of major importance for them to reach controlled symptoms and controlled disease of their ill child. They mentioned that controlling symptoms was of major relevance for maximal comfort for their child or at least that inconveniences were minimised as much as possible. Additionally, they mentioned that controlling the disease was a matter of preventing loss of their child or maximally prolonging their child's life. At some point during the disease process, parents were informed by HCPs that cure from the disease or preserving life of their child was no longer possible. Despite this information, many parents, both from the MD and NMD group, still had the ambition to find possible treatments to control their child's disease. Therefore, parents constantly worked to reduce, relieve or prevent symptoms of the disease and side effects of the treatment and also searched for optimal treatment to prevent further progression of the disease. When parents believed that controlling the disease was no longer a realistic aim, their focus shifted towards merely comfort care, whereby symptom control remained important.

\section{A life worth living}

Despite their focus on controlled symptoms and controlled disease, parents emphasised seeing their child as a beloved person who deserves a life worth living for the time that is left. They wanted their child to have fun, enjoy his/her life and make as much out of his/her life as possible. Most parents felt challenged to create a life worth living for their child. Especially when their child had limited abilities or when their child deteriorated and
Fig. 1 Aims and tasks of parents caring for a child with a LLD
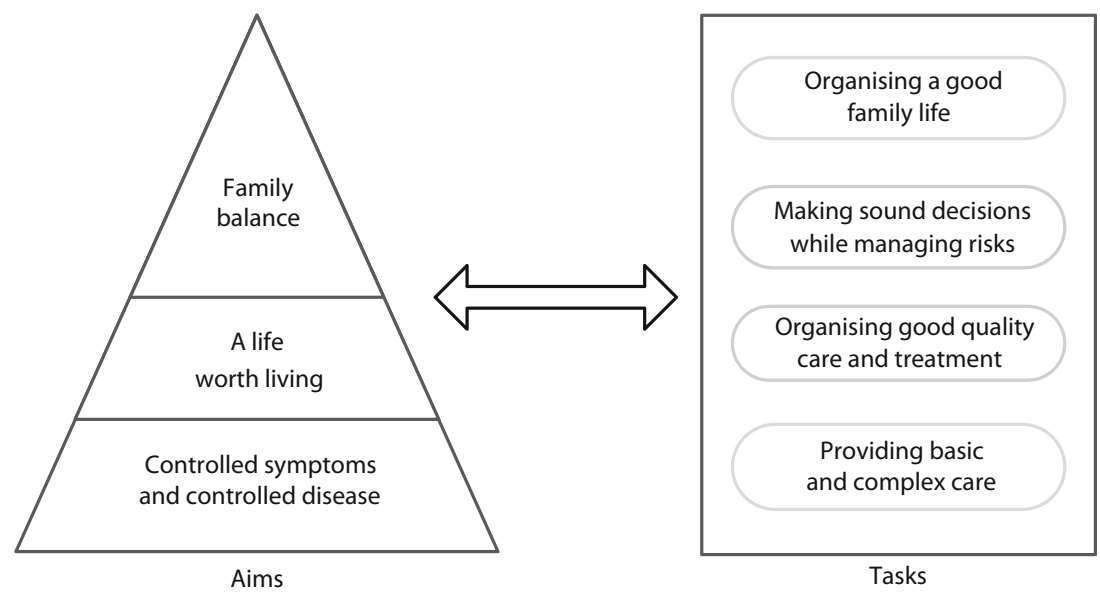
Table 3 Quotes that illustrate the parents' wish to be a 'good parent' and the parents' aims in the care for their child with a LLD, chosen from eight interviews with parents

\begin{tabular}{|c|c|}
\hline Theme & Quote \\
\hline Being a good parent & $\begin{array}{l}\text { Case 7: boy, } 9 \text { years, NMD. Father: When he dies, if he could think, this is the way it had to be, it sucks that I had this } \\
\text { disease but I could not have had better parents with this disease, to go this route with me. That should be his } \\
\text { conclusion on the last day. } \\
\text { Case 23: boy, } 4 \text { years, MD. Father: It takes a lot of energy to have such a child, besides that the care takes a lot of } \\
\text { energy. You are going to think about many things, whether you like it or not. Do I mind it? No, I do not mind it } \\
\text { because he deserves everything, he deserves the best, so I do everything for him. Yes, we give him whatever we can } \\
\text { give him. It just takes a lot of energy, that's all. So we are exhausted when we go to sleep in the evening, you are } \\
\text { exhausted. But I do not mind. }\end{array}$ \\
\hline $\begin{array}{l}\text { Controlled symptoms and } \\
\text { controlled disease }\end{array}$ & $\begin{array}{l}\text { Case 21: girl, } 3 \text { years, NMD. Mother: You also want her not to be sick too often, that she has energy, because that } \\
\text { was a problem for a long time. For that reason she started the night ventilation. And you see she has more energy } \\
\text { and feels good and she has less pneumonia and lower respiratory tract infection, and that was absolutely the main } \\
\text { goal. And that remains the goal, to have her as well as possible and that she can enjoy life as much as possible. } \\
\text { Case 20: girl, } 6 \text { years, MD. Mother: Last week I contacted the doctor, via a telephone consultation, because I found } \\
\text { that she was deteriorating, she started choking, drooled a lot. And her speech was worse. So since last week, in } \\
\text { consultation with the doctor, we started the Dexamethasone again. And again today a telephone consultation with } \\
\text { her about how it is now and whether that is enough. }\end{array}$ \\
\hline A life worth living & $\begin{array}{l}\text { Case 2: girl, } 4 \text { years, NMD. Father: My only concern is that she can have fun and enjoy herself and whether that is } \\
\text { with a clothes pin or with a ball, having fun is the most important to me. Then this is feasible for her and then it is } \\
\text { ok. } \\
\text { Case 23: boy, } 4 \text { years, MD. Mother: Yes, that he has time for as long as possible, and can be light-hearted and have } \\
\text { fun, enjoy himself, enjoy being together. That he can enjoy the little things. That we can do the things that give him } \\
\text { energy. And yeah, that he is having a good time. }\end{array}$ \\
\hline Family balance & $\begin{array}{l}\text { Case 14: girl, } 1 \text { year, NMD. Father: Since the birth of Maaike, life has been like riding a large high-speed train going } \\
400 \mathrm{~km} \text { an hour. And it is very difficult to relax and be there for each other. Look, the most important thing is } \\
\text { Maaike and her well-being, but we also have to be there for each other, so Machteld (mother) and I have to work } \\
\text { to maintain our relationship, otherwise it will go wrong. But right now being there for each other is proving very } \\
\text { difficult. And we both know that we have to do that... but well, Maaike is currently recovering from an illness, and } \\
\text { we currently do not dare to leave her in other people's care. So the decision is very simple, you choose Maaike. But } \\
\text { we do know that it's very important to go out for an evening, to go out to dinner together, to be with each other. But } \\
\text { yeah, right now that's not possible. } \\
\text { Case 13: boy, } 5 \text { years, MD. Mother: talking about the time that her son received chemotherapy: It was just very tough } \\
\text { for everyone, also for Jayden (sibling, } 6 \text { years), because he had to miss us very often because he was with his } \\
\text { grandparents. Yeah and we do not want that anymore. [...] Jayden, he has to be ok, he has to come out as } \\
\text { unscathed as possible, to come through it. To some extent this is not possible, but you need to support him in the } \\
\text { best possible way. }\end{array}$ \\
\hline
\end{tabular}

Some quotes are slightly modified to improve readability. Names are fictitious

$M D$ malignant disease, $N M D$ non-malignant disease

lost his/her abilities for life fulfilment, parents put even more efforts towards creating a life worth living.

\section{Family balance}

Parents aimed a variety of aspects that could be categorised as family balance. Family balance is a situation in which all individual family members can keep going, experience wellbeing and are able to develop within their full potential. It also contains established parental responsibilities, such as earning an income or organising a holiday.

Parents felt challenged in achieving this aim because they continuously had to adapt to the demanding care situation and to rearrange family life, while meeting the needs and interests of all family members involved. They mentioned that they had to deal with the limited flexibility in daily life, the disruption of the self-evident togetherness of their family and the siblings' need for attention. Most parents could not immediately leave home for spontaneous or unexpected activities because they needed more time in advance to schedule and prepare activities than 'healthy' families. Planned activities often needed cancelling, for instance when symptoms of their child suddenly worsened. Due to the extensive involvement in childcare and the intensive use of healthcare facilities, including hospitalisations, the opportunity to be together as a family was limited. Parents felt forced to give priority to the needs of their ill child, thus the siblings often came in second place. Many parents noticed that siblings received less attention and often had to wait until they had finished the care, which they could not postpone, for their ill child. Parents felt uncomfortable about this situation but often 
Table 4 Quotes that illustrate the parents' tasks in the care for their child with a LLD, chosen from eight interviews with parents

Theme Quote

Providing basic and complex care

Organising good quality care and treatment

Making sound decisions while managing risks

Organising a good family balance

Some quotes are slightly modified to improve readability. Names are fictitious

$M D$ malignant disease, $N M D$ non-malignant disease

lacked the opportunity to act otherwise given the urgency of the needs of their ill child.

\section{Struggling to achieve all aims}

From the parents' stories, it could be concluded that they became aware of the three aims over time. In addition, they experienced difficulties in balancing the aims because they tried to achieve the three aims at the same time.

\section{Becoming aware of the aims}

Parents mentioned how, initially, they were fully occupied by the aim of controlled symptoms and controlled disease as first priority. Parents emphasised that they, in their perspective, had learnt how to control the symptoms and to limit the burden and progression of the disease and how to respond to their child's care needs. During this learning process, many parents had felt thrown back on their own. However, they became familiar with the disease, the treatment options, their child's 
special needs and preferences, the healthcare system and what the new world of their child entailed. Most parents had developed their ability to assess, decide on and perform all diseaserelated tasks; however, some parents continued to struggle with the complexity of achieving controlled symptoms and controlled disease and felt uncertain, particularly when the disease progressed or when complications occurred.

For parents, the focus on creating a life worth living for their child was boosted once the LLD was diagnosed or, in $\mathrm{MD}$, when it became clear for parents that treating cancer was no longer considered to be effective. From the start of their child's disease, most parents intuitively felt the importance of a family balance. However, they accepted the disrupted family balance because their first and second aim of controlling symptoms and controlling disease and living a meaningful life had priority. Family balance obtained a clearer focus when the disease trajectory lasted longer and when the disease and symptom management and the child's well-being were at a manageable level.

\section{Balancing the aims}

In the context of their child's inevitable death, parents wanted to do everything as well as possible and tried to maximise all separate aims. However, they experienced that the efforts for creating a life worth living for their ill child and achieving a family balance were easily overruled by the efforts for controlling symptoms and, if possible, controlling disease, because the child's symptoms or disease always intruded to the foreground. Consequently, controlled symptoms and controlled disease appeared to stay the predominant aim for parents.

A life worth living for their ill child was the second dominant aim. Parents mainly succeeded herein when they, in their perspective, had controlled the symptoms and, if possible, the disease. Only when their child's death was near, some parents ignored their first aim in order to create a life worth living. For example, while their child had pain and wanted to play with friends, parents decided to delay the start of pain medication in order to enable their child to experience life fulfilment instead of being asleep as a side effect of the medication.

Achieving the first and second aim was a prerequisite to work towards a family balance. Therefore, many parents described their family balance as fragile, as it was rapidly disturbed by an increase of the symptoms, progression of the disease or a decrease of the child's well-being. In these situations, the aim for a family balance was easily overruled by the parents' need to control the symptoms and, if still realistic, to control the disease and by their ideal of a meaningful life.

Because parents tried to achieve all three aims, they had to keep several balls in the air at the same time. Some parents became aware of the necessity to balance between the aims, were able to develop themselves herein and increasingly took direction to achieve all three aims. For example, some parents realised that they also needed to give attention to their partner, other children and/or friends; otherwise, all these relations would be lost after their child's death. Other parents felt overwhelmed by the multiplicity and complexity of the first aim and were not able to look beyond controlling their child's symptoms and disease.

\section{Tasks}

With maximal commitment, parents performed many intertwined tasks, originating from the child's disease and the abovementioned aims. Four groups of tasks were identified: (1) providing basic and complex care, (2) organising good quality care and treatment, (3) making sound decisions while managing risks and (4) organising a good family life. The accomplishment of the tasks by parents determined the level of achievement of their aims, varying per family and child.

\section{Providing basic and complex care}

For many parents, the caregiving tasks to achieve controlled symptoms and controlled disease and to create a life worth living were unavoidable and numerous. The caregiving tasks consisted of assisting in the child's activities of daily living (ADL), symptom management, medical technical procedures, offering sleep support, supporting well-being and creating life fulfilment for their child. Many parents described how they learnt to provide complex medical care, such as preparing and providing medication, suctioning, giving tube feeding or fixing a prosthesis. These procedures needed to be attuned to their child's needs, abilities, coping strategies and learned routines and rituals to help him/her to accept undergoing the procedures of which some were life sustaining.

All parents felt the need and took their responsibility to monitor the child's physical condition and well-being and to intervene adequately when needed. Consequently, parents had limited control over their efforts for controlled symptoms and controlled disease, including how these efforts influenced their daily life. Besides this responsibility, parents emphasised that they considered themselves as being the best carers because they cared with parental love attuned to their child's needs. Therefore, they found it difficult to leave (complex) care to others, such as HCPs or informal carers. Many parents mentioned that even when they were supported by homecare nurses or during hospitalisations, they still provided many components of care. Additionally, when HCPs or informal carers became involved, parents had to guide them towards providing the care for their child attuned to his/her needs.

The intensity of providing basic and complex care largely varied per family and child and throughout the disease trajectory. Some parents could not lose their child out of sight to prevent the risk of severe life-threatening situations, which 
resulted in 24-h per day caring for their child, whereas others provided mainly routine childcare and facilitated their child to attend school.

\section{Organising good quality care and treatment}

Many parents emphasised how they had searched for the best treatment and professional support. They coordinated care and care facilities and arranged many practical things, such as equipment, reimbursements and medication at home. Some parents also arranged things, such as a special computer or toys, to enable their child to communicate and to develop, which potentially improved the child's well-being. Over time, some parents arranged (more) homecare to have some respite in favour of having time for the siblings or themselves (family balance).

Because parents felt final responsible for their child and family, they primarily performed this task. Many parents described this task as time-consuming and difficult because it was an ongoing process, even when their child was stable, and it never succeeded at once. Also, many actors and organisations were involved in creating well-organised childcare, making this task even more complex. Moreover, parents mentioned that this task required many efforts and valuable time, which they preferred to spend with their child. Especially when their child's death was near, parents wanted to enjoy the time left together with their child and not being busy with arranging care and practical things.

\section{Making sound decisions while managing risks}

Parents described that they made numerous, both minor and major, decisions in daily life aimed at maximising accomplishment of the three aims. For example, "is it safe enough to let my 15-year-old son take a shower by himself despite the risk of falling due to his amputated leg?" Because some parents, for instance, decided to accept day care to gain time for the siblings or to let their child attend school because he/she did enjoy this, their ability to control the disease and symptoms according to their own standards could decrease. Therefore, many parents often felt forced to weigh arguments, consider alternatives and make decisions to achieve a justifiable balance between their aims.

Especially, making decisions entailed weighing the major risks of losing their child. Parents explained how they decided to maximally protect their child by reducing the risk of worsening the symptoms and/or the disease or provoking a lifethreatening situation. This often resulted in protective behaviour that increased their workload. For example, some parents avoided day care to minimise the risk of infection. At other occasions, parents consciously chose not to emphasise the control of symptoms and control of disease and accepted a possible risk of deterioration in favour of a life worth living or a good family balance.
Because parents felt responsible for making the right decisions, they often felt tensions, particularly when they had to make decisions that allowed EOL to come or when they had to choose the least bad option. For instance, when new symptoms appeared, they had to choose between accepting the increase of the symptom load of their child or adapting medication running the risk of new or increased side effects. Many parents told that by moments, they felt overwhelmed by the large amount of decisions they had to make and felt overruled by the type and the impact of decisions and the short period of time they had available for making these far-reaching decisions. Some parents mentioned they had to negotiate for sufficient time until they felt comfortable to make a sound decision.

\section{Organising a good family life}

Most parents described that having a child with a LLD affected all family members. In favour of a family balance, they tried to integrate their extraordinary situation in daily life. They supported their child to attach to normal life or embedded their situation in a life as normal as possible. To relieve their workload, many parents chose to divide the caregiving tasks and the responsibility of earning an income. This could result in feelings of shortcoming and having lost relevant aspects of personal development, for one or both parents.

Many parents described they discovered in particular that rhythm and routines were helping in integrating caregiving in daily life. Rhythm took form of a daily pattern, providing guidance in the things that had to be done, such as wake up in time, providing childcare, cooking, housekeeping and bringing the children to school. Routines were tasks where they no longer had to think about and which became part of their pattern, for example how to prepare medication or when to give tube feeding. Parents told that by applying family rhythm and childcare routines, they gained time and energy for other activities.

When parents were aware of their aim for a family balance, they continuously had to weigh the needs of the individual family members. Sometimes, this meant that they had to reorganise care in favour of the family balance. For example, parents decided that when their child would be hospitalised again, one of them stayed with their child and one of them stayed at home with the siblings to pay them proper parental attention and stay connected. This choice came instead of staying in the hospital of both parents and letting the siblings stay at their grandparents as they did before.

\section{Discussion}

We identified that, based on their ambition to be a good parent in a situation where parents tried to prevent child loss and had to direct child loss in the end, parents strived for three main 
aims in caring for their child with a LLD. Parents primarily aimed for optimal controlled symptoms and controlled disease. Over time, the aims of a life worth living and a family balance gained importance. Since the time with their child is finite, parents developed a major need to concurrently achieve each separate aim and felt under pressure because everything had to be as good as possible. However, they could not always succeed herein, resulting in considerable distress for parents. To achieve the three aims, parents performed four interconnected tasks: providing basic and complex care, organising good quality care and treatment, making sound decisions while managing risks and organising a good family life. These tasks were relentless for parents because the accomplishment of the tasks determined the level of achievement of the aims. Although MD and NMD and their disease trajectories differed, the aims and tasks as experienced by parents in both groups were quite similar.

From this study, it follows that being a good parent included not only maintaining their child's health and ensuring that their child had a good life, which is earlier described [10, 24, 46, 47] but also achieving a situation in which all family members could keep going and experienced well-being. This study adds that the parents' aims not only guided parental caregiving but also encouraged them to leave no stone unturned to achieve all these aims, particularly controlled symptoms and controlled disease and a life worth living. As such, many parents were absolutely involved in childcare and ran the risk of a suppressed family life. In addition, the pressure for parents accumulated by doing the utmost in a limited time while also creating a rewarding time. These aspects contributed, together with the threat of future child loss, to the parents' distress and could be an explanation for the increased risk of a PTSD $[19,32]$.

Some of the identified parental tasks are earlier reported but not yet in a comprehensive overview within the context of PPC as was done in this study. Like others, we found that parents felt largely responsible to provide childcare by themselves no matter how complex it is $[4,6,11,12,44,47,48]$ and did everything to organise the best quality of care and treatment for their child. Parents also organised a good family life, which was creating time for themselves and their partner and, consistent with earlier research, maintaining any sense of normal life [6] and emotionally supporting their child and the siblings [4, 21, 27, 39]. Parents felt that succeeding in their tasks largely depended on their own efforts, even when they were supported by HCPs. However, their wish to be a good parent was a powerful internal motivator to conduct all tasks, as was till now only indicated in paediatric oncology $[10,13]$.

Many parents had felt abandoned and had difficulty in searching for the diagnosis and the best treatment, and in developing parental caregiving, which is in line with studies addressing parents' role to 'navigate uncharted territory' [15, 37, 47]. Parents mentioned this as exhausting and stressful at times, as was also described by Woodgate et al. [47]. It was seen that parents became experts in their child's care attuned to his/her needs; however, many of them (had) felt disrupted and sometimes powerless to improve their child's and own situation. Parents felt tensions in searching for support on the one hand and the burden of this support on the other hand, due to the limited time left with their child and the risk of a rapid disruption of their situation. Parents wanted to be there for their child and strived for preserving their parenting role and relationship with their child. Consequently, consistent with previous studies, parents found it difficult to entrust the care to informal caregivers or HCPs who, in their perception, may lack the ability to provide care at the same level as they do $[6,45,47]$. By refusing to withdraw from their caregiving tasks, some parents sacrificed their emotional and physical well-being, as previously described $[6,13]$.

This study showed that it is not only the complex palliative and EOL decisions but also the numerous minor decisions related to daily hassles that required attention and efforts from parents. Many parents felt inexperienced and overwhelmed to make complex and difficult EOL decisions in a limited period of time, as was also seen by Hinds et al. and Carnevale et al. $[5,10]$. This study adds that parents also made many smaller decisions, whereas PPC research mainly focuses on EOL decisions $[5,7,9,10,41,42]$. While making minor decisions, parents weighed the risks and the aims in daily life because every minor decision could have a major impact on controlling the symptoms and/or disease and the quality of life of their child and family. A further exploration of parental decision-making during the palliative phase could be helpful.

This study had some strengths and limitations. It was noticed that some HCPs prevented or delayed participation of eligible parents because they considered them too vulnerable or burdened, which is known as gate keeping and often seen in palliative care research [17]. This might have resulted in an underestimation of the parents' difficulties and efforts to achieve the aims and to perform all tasks. The sample mainly consisted of native Dutch parents of one university hospital. Differing cultural and ethnic backgrounds were not captured. Nevertheless, we included both mothers and fathers and our sample showed a wide variation in diagnosis and phase of the palliative trajectory. In addition, we were able to provide the perspective of parents who currently cared for their child with a LLD. These aspects enabled us to give a realistic and comprehensive overview of parental caregiving in PPC. Our sample included a relatively large amount of children with NMD. This might have resulted in an overestimation of providing basic and complex care throughout the entire palliative trajectory because these children appeared to be more dependent on parental care for ADL than children with MD. Although Dutch people are relatively highly educated, in this study, they were overrepresented. Highly educated parents might be more capable in searching for and organising the best care for their child and might be more able to take over homecare tasks because their professional 
positions provided them the flexibility to do so. Therefore, in reality, the parental distress following from the aims and tasks might be even higher than seen in this study. On the other hand, it was noticed that in many families (irrespective of their education level), one parent and during the EOL phase often both parents quitted their job, which in most cases is partially financially supported by the Dutch government, enabling parents of seriously ill children to provide childcare at home.

\section{Implications for practice}

This study shows more in-depth what parents face and how they combine parenting and caregiving. In addition to the PPC that professionals currently provide to the child and family, it could be helpful to discuss at times on a meta-perspective with parents the content of parental aims, the related tasks and the bottlenecks from both the parents' and professionals' perspective. This is preferably done from the start of the disease trajectory to decrease parents' distress and to strengthen their resilience, since the awareness of their child's LLD often overwhelms them. Based on the meta-perspective, an exploration of what is needed for parents to succeed at home can be made and organised by the parents and their homecare team together with a PPCT. Therefore, they have to define and organise the help and support in a way that is acceptable for and provides relief to parents. For example, help in the household or for other daily tasks or someone to bring a sibling to school or sports. The support should be provided by a (healthcare) professional whom parents trust and who gives active direction to the parents while at the same time not taking over their parenting role. By doing so, PPC becomes tailored to the individual needs of families in PPC and better accepted.

Acknowledgements We thank all the parents who participated in this study. We also thank Madelief Buijs for conducting the first interviews and Doris Verwijmeren, who supported us as a research assistant, for coding the transcripts.

\section{Authors' contributions}

- Conception or design of the work: all authors

- Data collection: LV, MK

- Data analysis and interpretation: LV, MK, JvD

- Drafting the article: LV, MK

- Critical revision of the article: MK, ASM, DB, DC, MG, JvD

- Final approval of the version to be published: all authors

\section{Compliance with ethical standards}

Conflict of interest The authors declare that they have no conflict of interest.

Funding The study was sponsored by the Netherlands Organisation for Health Research and Development (ZonMw), Grant Number 82-8210098-208. The authors declare that they have no financial relationship with this organisation that sponsored the research.
Ethical approval All procedures performed in studies involving human participants were in accordance with the ethical standards of the institutional and/or national research committee and with the Helsinki Declaration and its later amendments or comparable ethical standards.

Informed consent Informed consent was obtained from all individual participants included in the study.

Open Access This article is distributed under the terms of the Creative Commons Attribution 4.0 International License (http:// creativecommons.org/licenses/by/4.0/), which permits unrestricted use, distribution, and reproduction in any medium, provided you give appropriate credit to the original author(s) and the source, provide a link to the Creative Commons license, and indicate if changes were made.

\section{References}

1. ACT (2009) A guide to the development of children's palliative care services, third edit. Bristol, UK

2. Bluebond-Langner M, Belasco JB, Goldman A, Belasco C (2007) Understanding parents' approaches to care and treatment of children with cancer when standard therapy has failed. J Clin Oncol 25: 2414-2419. doi:10.1200/JCO.2006.08.7759

3. Braun V, Clarke V (2006) Using thematic analysis in psychology. Qual Res Psychol 3:77-101. doi:10.1191/1478088706qp063oa

4. Canam C (1993) Common adaptive tasks facing parents of children with chronic conditions. J Adv Nurs 18:46-53. doi:10.1046/j.13652648.1993.18010046.x

5. Carnevale F, Canouï P, Hubert P, Farrell C, Leclerc F, Doussau A, Seguin M-J, Lacroix J (2006) The moral experience of parents regarding life-support decisions for their critically-ill children: a preliminary study in France. J Child Health Care 10:69-82. doi:10.1177/1367493506060209

6. Collins A, Hennessy-Anderson N, Hosking S, Hynson J, Remedios C, Thomas K (2016) Lived experiences of parents caring for a child with a life-limiting condition in Australia: a qualitative study. Palliat Med 30:950-959. doi:10.1177/0269216316634245

7. De Vos MA, Bos AP, Plotz FB, van Heerde M, de Graaff BM, Tates K, Truog RD, Willems DL (2015) Talking with parents about endof-life decisions for their children. Pediatrics 135:e465-e476. doi:10.1542/peds.2014-1903

8. Dierckx de Casterle B, Gastmans C, Bryon E, Denier Y (2012) QUAGOL: a guide for qualitative data analysis. Int J Nurs Stud 49:360-371. doi:10.1016/j.ijnurstu.2011.09.012

9. Hinds PS, Oakes L, Furman W, Quargnenti A, Olson MS, Foppiano P, Srivastava DK (2001) End-of-life decision making by adolescents, parents, and healthcare providers in pediatric oncology: research to evidence-based practice guidelines. Cancer Nurs 24:122136. doi: 10.1097/00002820-200104000-00007

10. Hinds PS, Oakes LL, Hicks J, Powell B, Srivastava DK, Spunt SL, Harper J, Baker JN, West NK, Furman WL (2009) "Trying to be a good parent" as defined by interviews with parents who made phase I, terminal care, and resuscitation decisions for their children. J Clin Oncol 27:5979-5985. doi:10.1200/JCO.2008.20.0204

11. Jerrett MD (1994) Parents' experience of coming to know the care of a chronically ill child. J Adv Nurs 19:1050-1056. doi:10.1111 /j.1365-2648.1994.tb01187.x

12. Jones BL (2012) The challenge of quality Care for Family Caregivers in pediatric cancer care. Semin Oncol Nurs 28:213220. doi:10.1016/j.soncn.2012.09.003

13. Kars MC, Duijnstee MSH, Pool A, van Delden JJM, Grypdonck MHF (2008) Being there: parenting the child with acute 
lymphoblastic leukaemia. J Clin Nurs 17:1553-1562. doi:10.1111 /j.1365-2702.2007.02235.x

14. Kars MC, Grypdonck MHF, Beishuizen A, Meijer-van Den Bergh EMM, Van Delden JJM (2010) Factors influencing parental readiness to let their child with cancer die. Pediatr Blood Cancer 54: 1000-1008. doi:10.1002/pbc.22532

15. Kars MC, Grypdonck MHF, van Delden JJM (2011a) Being a parent of a child with cancer throughout the end-of-life course. Oncol Nurs Forum 38:E260-E271. doi:10.1188/11.ONF.E260-E271

16. Kars MC, Grypdonck MHF, De Korte-Verhoef MC, Kamps WA, Meijer-Van Den Bergh EMM, Verkerk MA, Van Delden JJM (2011b) Parental experience at the end-of-life in children with cancer: "preservation" and "letting go" in relation to loss. Support Care Cancer 19:27-35. doi:10.1007/s00520-009-0785-1

17. Kars MC, van Thiel GJMW, van der Graaf R, Moors M, de Graeff A, van Delden JJM (2016) A systematic review of reasons for gatekeeping in palliative care research. Palliat Med 30:533-548. doi:10.1177/0269216315616759

18. Kassam A, Skiadaresis J, Alexander S, Wolfe J (2014) Parent and clinician preferences for location of end-of-life care: home, hospital or freestanding hospice? Pediatr Blood Cancer 61:859-864. doi:10.1002/pbc. 24872

19. Kazak AE, Noll RB (2015) The integration of psychology in pediatric oncology research and practice: collaboration to improve care and outcomes for children and families. Am Psychol 70:146-158. doi:10.1037/a0035695

20. Kazak AE, Kassam-Adams N, Schneider S, Zelikovsky N, Alderfer MA, Rourke M (2006) An integrative model of pediatric medical traumatic stress. J Pediatr Psychol 31:343-355

21. Kelly KP, Wells DK, Chen L, Reeves E, Mass E, Camitta B, Hinds PS (2013) Caregiving demands and well-being in parents of children treated with outpatient or inpatient methotrexate infusion: a report from the Children's Oncology Group. J Pediatr Hematol Oncol 36:495-500. doi:10.1097/MPH.0b013e31828b0947

22. Kvale S (1996) InterViews: an introduction to qualitative research interviewing. SAGE publications, Thousand Oaks, California

23. Matsuoka M, Narama M (2012) Parents' thoughts and perceptions on hearing that their child has incurable cancer. J Palliat Med 15: 340-346. doi:10.1089/jpm.2011.0410

24. Maurer SH, Hinds PS, Spunt SL, Furman WL, Kane JR, Baker JN (2010) Decision making by parents of children with incurable cancer who opt for enrollment on a phase I trial compared with choosing a do not resuscitate/terminal care option. J Clin Oncol 28:32923298. doi:10.1200/JCO.2009.26.6502

25. McConnell D, Savage A (2015) Stress and resilience among families caring for children with intellectual disability: expanding the research agenda. Curr Dev Disord Rep 2:100-109. doi:10.1007 /s40474-015-0040-z

26. Monterosso L, Kristjanson LJ (2008) Supportive and palliative care needs of families of children who die from cancer: an Australian study. Palliat Med 22:59-69. doi:10.1177/0269216309104060

27. Mooney-Doyle K, Deatrick JA (2016) Parenting in the face of childhood life-threatening conditions: the ordinary in the context of the extraordinary. Palliat Support Care 14:187-198. doi:10.1017/S1478951515000905

28. Morse JM, Field PA (1996) Nursing research: the application of qualitative approaches, 2nd edn. Chapman \& Hall, London

29. Morse JM, Barrett M, Mayan M, Olson K, Spiers J (2002) Verification strategies for establishing reliability and validity in qualitative research. Int J Qual Methods 1:13-22. doi:10.1063/1.2011328

30. Nightingale R, Friedl S, Swallow V (2015) Parents' learning needs and preferences when sharing management of their child's longterm/chronic condition: a systematic review. Patient Educ Couns 98:1329-1338. doi:10.1016/j.pec.2015.05.002
31. Pousset G, Bilsen J, Cohen J, Addington-Hall J, Miccinesi G, Onwuteaka-Philipsen B, Kaasa S, Mortier F, Deliens L (2010) Deaths of children occurring at home in six European countries. Child Care Health Dev 36:375-384. doi:10.1111/j.13652214.2009.01028.x

32. Price J, Kassam-Adams N, Alderfer MA, Christofferson J, Kazak AE (2016) Systematic review: a reevaluation and update of the integrative (trajectory) model of pediatric medical traumatic stress. J Pediatr Psychol 41:86-97. doi:10.1093/jpepsy/jsv074

33. Ray LD (2002) Parenting and childhood chronicity: making visible the invisible work. J Pediatr Nurs 17:424-438. doi:10.1053 jpdn.2002.127172

34. Rolland JS, Walsh F (2006) Facilitating family resilience with childhood illness and disability. Curr Opin Pediatr 18:527-538. doi:10.1097/01.mop.0000245354.83454.68

35. Rosenberg AR, Baker KS, Syrjala KL, Back AL, Wolfe J (2013a) Promoting resilience among parents and caregivers of children with cancer. J Palliat Med 16:645-652. doi:10.1089/jpm.2012.0494

36. Rosenberg AR, Dussel V, Kang T, Geyer JR, Gerhardt CA, Feudtner C, Wolfe J (2013b) Psychological distress in parents of children with advanced cancer. JAMA Pediatr 167:537-543. doi:10.1001/jamapediatrics.2013.628

37. Steele R (2005) Navigating uncharted territory: experiences of families when a child is dying. J Palliat Care 21:35-43

38. Sulkers E, Tissing WJE, Brinksma A, Roodbol PF, Kamps WA, Stewart RE, Sanderman R, Fleer J (2015) Providing care to a child with cancer: a longitudinal study on the course, predictors, and impact of caregiving stress during the first year after diagnosis. Psychooncology 24:318-324. doi:10.1002/pon.3652

39. Svavarsdottir EK (2005) Caring for a child with cancer: a longitudinal perspective. J Adv Nurs 50:153-161. doi:10.1111/j.13652648.2005.03374.x

40. Thomas DR (2006) Method notes a general inductive approach for analyzing qualitative evaluation data. Am J Eval 27:237-246. doi:10.1177/1098214005283748

41. Tomlinson D, Capra M, Gammon J, Volpe J, Barrera M, Hinds PS, Bouffet E, Geenberg ML, Baruchel S, Llewellyn-Thomas HA, Sung L (2006) Parental decision making in pediatric cancer end-of-life care: using focus group methodology as a prephase to seek participant design input. Eur J Oncol Nurs 10:198-206. doi:10.1016/j.ejon.2005.11.003

42. Van Loenhout RB, van der Geest IMM, Vrakking AM, van der Heide A, Pieters R, van den Heuvel-Eibrink MM (2015) End-oflife decisions in pediatric cancer patients. J Palliat Med 18:697-702. doi:10.1089/jpm.2015.29000.rbvl

43. Vickers JL, Carlisle C (2000) Choices and control: parental experiences in pediatric terminal home care. J Pediatr Oncol Nurs 17:12 21. doi:10.1177/104345420001700103

44. Wang K-WK, Barnard A (2008) Caregivers' experiences at home with a ventilator-dependent child. Qual Health Res 18:501-508. doi:10.1177/1049732307306185

45. Wood F, Simpson S, Barnes E, Hain R (2010) Disease trajectories and ACT/RCPCH categories in paediatric palliative care. Palliat Med 24:796-806. doi:10.1177/0269216310376555

46. Woodgate RL (2006) Living in a world without closure: reality for parents who have experienced the death of a child. J Palliat Care 22: 75-82. doi:10.1097/01.NMC.0000288008.02877.f5

47. Woodgate RL, Edwards M, Ripat JD, Borton B, Rempel G (2015) Intense parenting: a qualitative study detailing the experiences of parenting children with complex care needs. BMC Pediatr 15:197. doi:10.1186/s12887-015-0514-5

48. Young B, Dixon-Woods M, Heney D (2002) Identity and role in parenting a child with cancer. Pediatr Rehabil 5:209-214. doi:10.1080/1363849021000046184 